\title{
Geo-Spatial Ground Water Quality Mapping and Assessment of Mining Region - A Case Study
}

\author{
Singha Soumya ${ }^{1}$, Verma. M. K², Singha Sudhakar ${ }^{3}$ \\ ${ }^{1}$ Assistant Professor, Department of Civil Engineering, RCET, Raipur, India \\ ${ }^{2}$ Vice Chancellor CSVTU, Bhilai (Professor, Department of Civil Engineering, NIT, Raipur), India \\ ${ }^{3}$ Assistant Professor, Department of Civil Engineering, REC, Raipur-India.
}

\begin{abstract}
In the present study, the impact of mining activities on groundwater quality around the Korba coalfields covering an area of $530 \mathrm{sq} . \mathrm{km}$ which lies between latitudes $22^{\circ} 15^{\prime}$ and $22^{\circ} 30^{\prime} \mathrm{N}$ and longitudes $82^{\circ} 15^{\prime} \mathrm{E}$ and $82^{\circ} 15^{\prime} \mathrm{E}$ in the state of Chhattisgarh, India was carried out. In this study water samples were collected during the year 2012. The analytical data collected from the sampling points of the well location were used as input data for Arc GIS 9.3 to prepare various thematic maps showing the spatial distribution of water quality and also for calculating water quality index (WQI). Attribute sensitivity analysis was also performed in this present study. Results indicate that most of the areas are highly affected by parameters such as $\mathrm{pH}$, Turbidity and Iron.
\end{abstract}

Keywords: Arc GIS, Ground water quality, Mining environment, WQI, Sensitivity analysis

\section{Introduction}

Groundwater is a pervasive and valuable resource. Subsurface water is an important component of water resource systems. Usually they are of excellent quality. Being naturally filtered in their way through the ground, they are generally clear, colorless, and free from microbial contamination and require minimal treatment. The quality of ground water deviates due to large number of individual hydrological, physical, chemical and biological factors. A threat is now posed by an ever-increasing number of soluble or dissolved chemicals from urban, industrial and from modern agricultural practices.

GIS has emerged as a powerful tool for storing, analyzing, and displaying spatial data and using these data for decision making in several areas including engineering and environmental fields ( Burrough and McDonnell, 1998; Lo and Yeung, 2003).GIS is used as an effective tool for developing solutions for water resources problems for assessing and mapping of ground water quality, understanding the natural environment and managing water resources on a required scale, assessing groundwater vulnerability to pollution. Ahn and Chon (1999) studied groundwater contamination and spatial relationships among groundwater quality, topography, geology, land use, and pollution sources using GIS in Seoul. Ducci (1999) produced groundwater contamination risk and quality maps by using GIS in Southern Italy. It was suggested that the use of this software is vital in testing and improving the groundwater quality assessment methods. Hong and Chon (1999) investigated groundwater contamination and spatial relationships among groundwater quality, topography, geology, land use and pollution sources in two sites namely Asan area and Gurogu area of Seoul city, Korea. Another interesting work was done by Anbazhagan and Nair 2005) developed groundwater quality mapping using the Geographic Information System (GIS) for Panvel basin of Raigarh district, Maharashtra, India for agricultural and drinking purposes. Ground water quality maps may be used to assist planners, managers, and local officials in evaluating the current scenario on whole ground water quality parameters.

In the present study one such attempt have been made to assess and map the quality of groundwater of surrounding mining region of Korba district Chhattisgarh by creating spatial reference to point locations for which the quality of groundwater is known in an integrated environment using GIS and by determining Water Quality Index (WQI).This index provides a way to communicate information on overall quality status of water to the concerned user community and policy makers. A WQI summarizes large amounts of water quality data into simple terms (excellent, good, bad, etc) for reporting to managers and the public in a consistent manner (Hulya, B et al., 2009).In addition to determination of water quality index, an objective procedure is framed to test the sensitivity of the proposed model. The capability of GIS is employed to implement the estimated WQI and to test the sensitivity of the model. The model sensitivity analysis indicates the parameter that reflects the lower water quality and those of significant spatial variability shows larger impacts on WQI and must be accurately and carefully mapped. GIS are designed to collect diverse spatial data to represent spatially variable phenomena by applying a series of overlay analysis of data that are in spatial register (Bonham-Carter, 1996).

\section{Study Area}

Korba district lies between Latitude $22^{0} 01^{\prime} 50^{\prime}$ ' to $23^{\circ}$ $01^{\prime} 20^{\prime \prime} \mathrm{N}$ and longitude $82^{\circ} 07^{\prime} 20^{\prime \prime}$ to $83^{\circ} 07^{\prime} 50^{\prime \prime} \mathrm{E}$ and its height from sea level $304.8 \mathrm{~m}$. Korba district boundary covers 7145.44 sq.km area. Korba district is located in East- central part of Chhattisgarh and is known as the power capital of State. Korba district comes under Bilaspur Division and is inhabited mainly by tribes including the protected tribe Korwas. The river Hasdeo-a tributary of Mahanadi - enters and flow through the district. River Hasdeo is the principal river of the district entering from Surguja district and 


\section{International Journal of Science and Research (IJSR) \\ ISSN (Online): 2319-7064 \\ Index Copernicus Value (2013): 6.14 | Impact Factor (2014): 5.611}

flowing through the rocky and wooded grounds of Matin Uprora and plain of Champa. Its total length is $233 \mathrm{~km}$. Base map of study area is prepared and shown in fig 1 . The study area covers 80.93 sq. $\mathrm{km}$ surrounding some parts of mining region. Mines area were Bagdeva, Delwadih, Singhali, Dipka, Gevra, Laxman, Balgi, Kusmunda, Korba, Manikpur, Rajgamar comes under Korba coalfields.

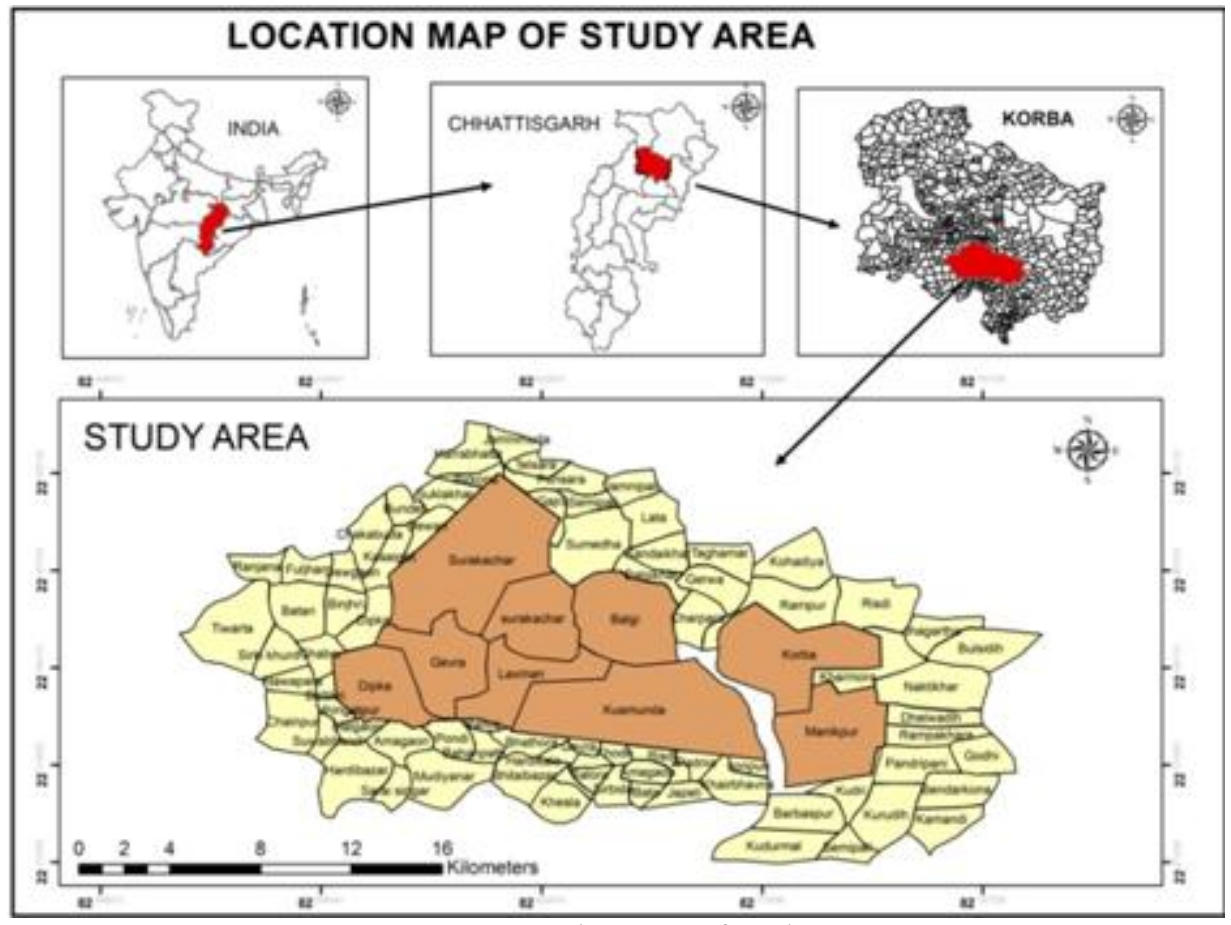

Figure 1: Location map of study area

\section{Data and Methods}

\subsection{Groundwater Quality Data}

This study utilizes ground water samples collected manually from bore wells, tube wells and dug wells which were approximately equally distributed all over 30 villages around mining region. The data set includes measurements of several physical and chemical parameters of sub surface water obtained by in-situ measurements and laboratory analytical techniques. More than 120 samples were collected and analyzed during the period of 2012. The ground water sampling location map collected from CGWB is shown in fig 2. The water sample collection had been done for 30 villages only. Quality analyses have been conducted as per standard procedures. All the water quality parameters are expressed in $\mathrm{mg} / \mathrm{l}$ except $\mathrm{pH}$ and turbidity. Each parameter was compared to desirable standard limit of that parameter stipulated for drinking water as prescribed by BIS Standards(1991) and WHO(1983) for drinking and public health purposes. Nine parameters such as $\mathrm{pH}$, Turbidity, TDS, Fe, Fl, $\mathrm{NO}^{-}, \mathrm{Ca}^{2+}$, $\mathrm{TH}$, and $\mathrm{Cl}^{-}$were selected from the data set to generate the Water Quality Index. Standards for drinking water were chosen as human health is taken as priority besides the high quality of drinking water makes it potable for much other other kind of purposes. Six parameters ( $\mathrm{Fe}, \mathrm{Fl}, \mathrm{Cl}^{-}, \mathrm{Ca}^{2+}$, $\mathrm{TH}, \mathrm{TDS}$ ) fall under the category of chemically derived contaminants that could alter the water taste, odour or appearance and affect its "acceptability" by consumers (WHO, 2004). One parameter (NO3) was listed under the category of chemicals that might inflict "potential health risk" and was assigned a guideline value of $45 \mathrm{mg} / \mathrm{l}$ and two parameters are physical parameters namely $\mathrm{pH}$, and
Turbidity. These two physical parameters also put a great influence on sustainability of water quality for various activities.

\subsection{Preparation of Spatial Database}

In order to capture the spatial variation of ground water quality in Korba district, spatial analysis with GIS was conducted. For the development of data base, twenty toposheets (64-J-1, 64-J-2,64-J-3, 64-J-5, 64-J-6, 64-J-7, 64J-8, 64-J-9, 64-J-10, 64-J-11, 64-J-12, 64-J-14, 64-J-15, 64-J$16,64-\mathrm{N}-2,64-\mathrm{N}-3,64-\mathrm{N}-4,64-\mathrm{K}-5,64-\mathrm{K}-9,64-\mathrm{K}-10)$ of 1:50000 scale covering the entire Korba district were geo referenced using four Control points. Based on the location data, location map of study area, point feature showing the position of 30 wells are marked and map for the same has been generated.

\subsection{Preparation of Non Spatial Database}

The study is carried out with the help of two major components: village boundary map and field data. The samples were tested using standard procedures in the laboratory and analyzed. The WQI value for each village was calculated. The ground water quality data thus obtained forms the non-spatial database for the present study. 


\section{International Journal of Science and Research (IJSR) \\ ISSN (Online): 2319-7064}

Index Copernicus Value (2013): 6.14 | Impact Factor (2014): 5.611

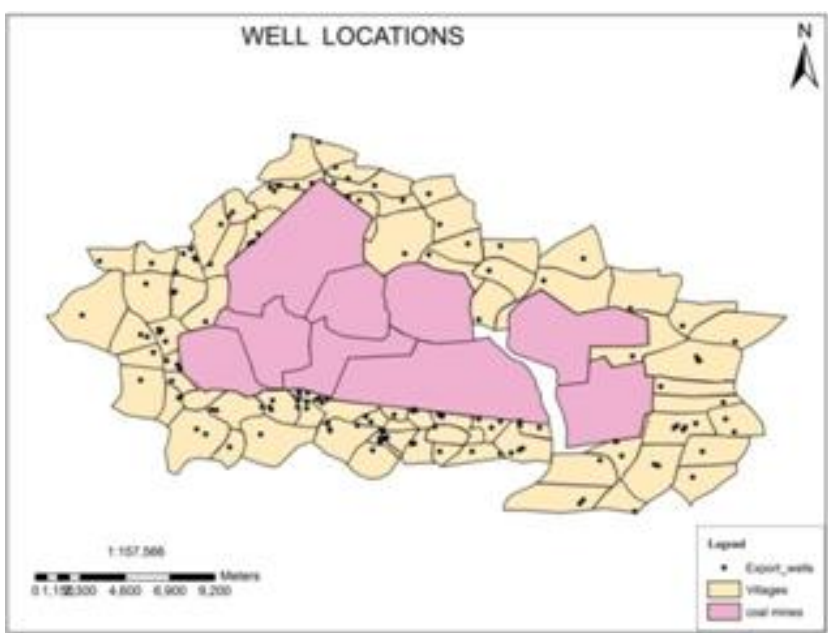

Figure 2: Groundwater sampling locations

\subsection{Determination of Water Quality Index}

Estimating of water quality index is to convert complex water quality data into information that is understandable and useable by public. Thus WQI is useful and effective method which can be known as an indicator of water quality. In the study, WQI was calculated by using the Weighted Arithmetic Index Method as described by (Cude, c et al., 2001). In this method, the water quality components are multiplied by weighting factor and then aggregated by simple arithmetic mean. For assessing the water quality in this study, first of all, the quality rating scale (Qi) for each parameter was estimated by using the following eq ,

$$
\mathrm{Qi}=\left\{\left[\left(\mathrm{V}_{\text {actual }}-\mathrm{V}_{\text {ideal }}\right) /\left(\mathrm{V}_{\text {standard }}-\mathrm{V}_{\text {ideal }}\right)\right] \times 100\right\}
$$

Where, Qi=Quality rating of ith parameter for total of $n$ water quality parameters

$\mathrm{V}_{\text {actual }}=$ Actual value of water quality parameter obtained from laboratory test

$\mathrm{V}_{\text {ideal }}=$ Ideal value of that same water quality parameter can be obtained from standard table

$\mathrm{V}_{\text {ideal }}$ for $\mathrm{pH}=7$ and for other parameters it becomes zero.

$\mathrm{V}_{\text {standard }}=$ Recommended BIS standard of water quality

parameter (BIS 10500., 1991) and shown in table 3.1

Then after estimating the quality rating scale $\left(Q_{i}\right)$, the Relative weight $\left(\mathrm{W}_{\mathrm{i}}\right)$ was estimated by a value inversely proportional to the recommended standard $\left(\mathrm{S}_{\mathrm{i}}\right)$ for the corresponding parameter using the following equation;

$$
\mathrm{W}_{\mathrm{i}}=1 / \mathrm{S}_{\mathrm{i}}
$$

Where, $\mathrm{W}_{\mathrm{i}}=$ Relative weight of $\mathrm{nth}$ parameter

$\mathrm{S}_{\mathrm{i}}=$ Standard permissible value of $n$th parameter

This implies that Relative Weight to various water quality parameters are inversely proportional to the recommended standards for the corresponding parameters. At last, the overall WQI was determined by aggregating the quality rating with the relative weight linearly by using the following expression;

$$
\mathrm{WQI}=\sum \mathrm{Q}_{\mathrm{i}} \mathrm{W}_{\mathrm{i}} / \sum \mathrm{W}_{\mathrm{i}}
$$

Table 1: Water Quality Parameter and their BIS Standards

\begin{tabular}{|l|c|}
\hline Parameter & Standard \\
\hline $\mathrm{pH}$ & 8.5 \\
\hline TURBIDITY(NTU) & 5 \\
\hline CHLORIDE(mg/l) & 250 \\
\left.\hline TOTAL HARDNESS(mg/l ${\left.\text { as } \mathrm{caco}_{3}\right)}\right)$ & 300 \\
\hline IRON(mg/l) & 0.3 \\
\hline FLUORIDE(mg/l) & 1.0 \\
\hline CALCIUM $(\mathrm{mg} / \mathrm{l})$ & 75 \\
\hline TDS $(\mathrm{mg} / \mathrm{l})$ & 500 \\
\hline NITRATE $(\mathrm{mg} / \mathrm{l})$ & 45 \\
\hline
\end{tabular}

In brief, WQI is generally defined for a specific and intended use of water. In this study the WQI was considered for human consumption and for drinking purpose. The maximum WQI for the drinking water was considered as 100 score. Based on the WQI values, the ground water quality is rated as excellent, good, poor, very poor and unfit/unsuitable for drinking and is shown in table 2.

Table 2: Water Quality Index Levels

\begin{tabular}{|c|c|}
\hline Water Quality Index & Description \\
\hline $0-50$ & EXCELLENT \\
\hline $51-100$ & GOOD \\
\hline $101-200$ & POOR \\
\hline $201-300$ & VERY POOR \\
\hline$>300$ & UNFIT FOR DRINKING(UFD) \\
\hline
\end{tabular}

\subsection{Generation of Maps}

The spatial and non spatial data bases generated were integrated for the generation of the spatial distribution maps of all water quality parameters including WQI map. The water quality data (non spatial data) is linked to the sampling location (spatial data) to develop various thematic maps.

\subsection{Sensitivity Analysis}

Geographical sensitivity analysis is defined as the study of the effects of imposed perturbations (variations) on the inputs of geographical analysis on the output of that analysis (Lodwick et al., 1990). A Geographical sensitivity analysis helps to determine what map(s) and/ or polygon(s) is (are) the most or least critical in finding out the values of output map. These critical maps or polygons denote where most/least care must/may be taken while preparing the input data in order to draw reliable conclusions from the output (Lodwicket al., 1990). In this study, attribute sensitivity was used to test the sensitivity of the WQI to a fixed percentage of perturbation introduced to each of the nine primary maps.

Attribute sensitivity: measures the overall magnitude of changes in the attribute values (WQI) from their "unperturbed" values. It may be concluded that, it describes the total absolute difference between the value of the correct WQI and the value of an erroneous WQI within an area.

$$
\mathrm{S}=\Sigma_{\mathrm{p}} \mathrm{S}_{\mathrm{p}}\left|\mathrm{r}_{\mathrm{p}}-\mathrm{r}_{\mathrm{p}}^{\prime}\right|\left(\text { area weighted measure, } \mathrm{S}_{\mathrm{p}}=\mathrm{A}_{\mathrm{p}}\right)
$$

where $r_{p}$ and $r^{\prime}$; are the attributes of the "unperturbed" and "perturbed" index, respectively in the designated polygon, $p$, $\mathrm{A}_{\mathrm{p}}$; is the area of the polygon resulting from the intersection of all rank maps to generate the final index.

\section{Volume 4 Issue 12, December 2015}




\section{Results and Discussion}

\subsection{Groundwater Quality Variation}

The value of $\mathrm{pH}$ in the ground water data collected varied from the range 5.05 to 8.00 .Most of the villages around mining region are having $\mathrm{pH}$ less than 6.5 covering an area of about $58.6 \mathrm{sq}$. $\mathrm{Km}(72.41 \%)$. This shows that ground water of study area is mainly acidic. The concentrations of turbidity are not within the range for most of the villages covering an area of about $49.28 \mathrm{sq}$. $\mathrm{km}(60.89 \%)$. Villages namely Dewari and Bahanpath, shows very high turbidity more than 80 NTU also. Out of 30 villages, only 4 villages are well within the range 0-5 NTU. The Iron content in the villages like Birkona, Dewgaon, Binjhari, Fuljhar, Nawapara, Harabhatta, are within the desirable limit below $0.3 \mathrm{mg} / \mathrm{l}$. 15 no of villages are found to be above permissible limit i.e. $>1.00 \mathrm{mg} / \mathrm{l}$. Iron concentration of above permissible limit spreads over an area of 42.1 sq. Km (52.02\%). Spatial distribution for $\mathrm{PH}$, Turbidity, and iron is shown in figures from 4 to 6 for the source data.

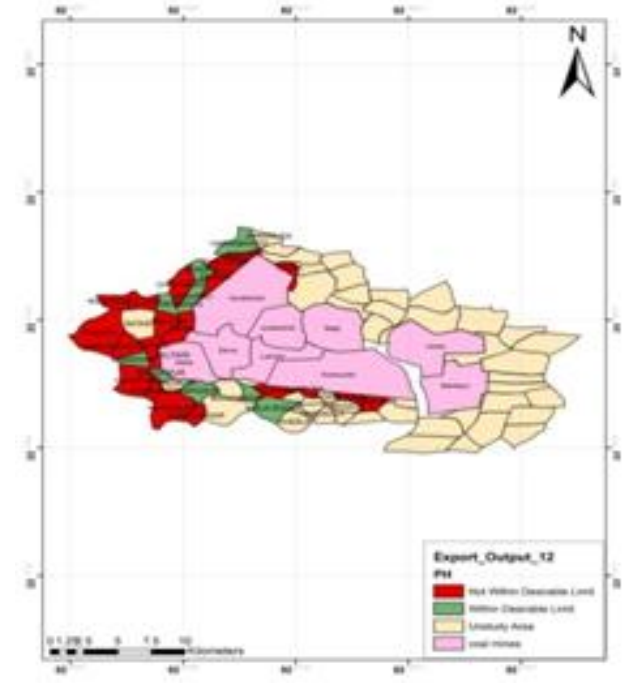

Figure 4: Spatial distribution of $\mathrm{pH}$.

\subsection{Water Quality Index}

WQI indicates the quality of water with reference to an index number which reflects the overall status of GWQ for drinking purposes. The overall view of WQI of the present study area show higher WQI. But only ten villages (33.33\%) had a satisfactory result of WQI below 100 and water present in seventeen villages $(56.66 \%)$ are found to be very poor having WQI 200 to 300 . The main reasons for the present situation may be due to presence of mining areas, misused ponds, open dumping of solid wastes, improper use of fertilizers. Spatial distribution of WQI is shown in Fig 7.

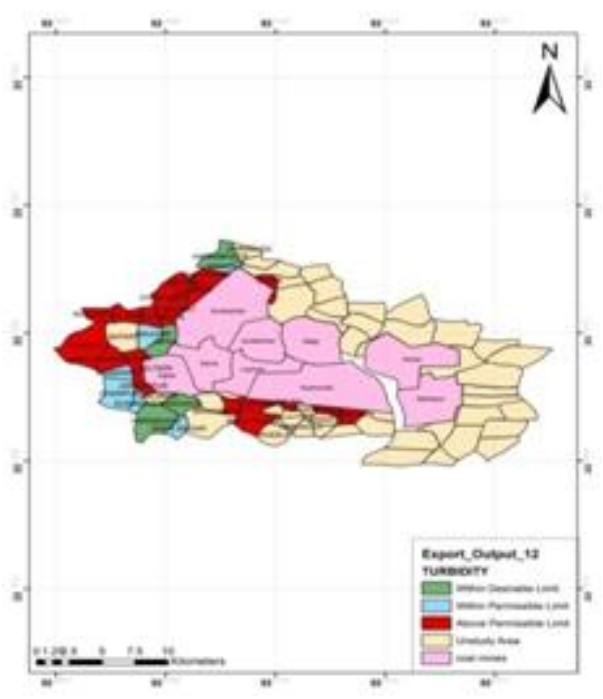

Figure 5: Spatial distribution of turbidity.

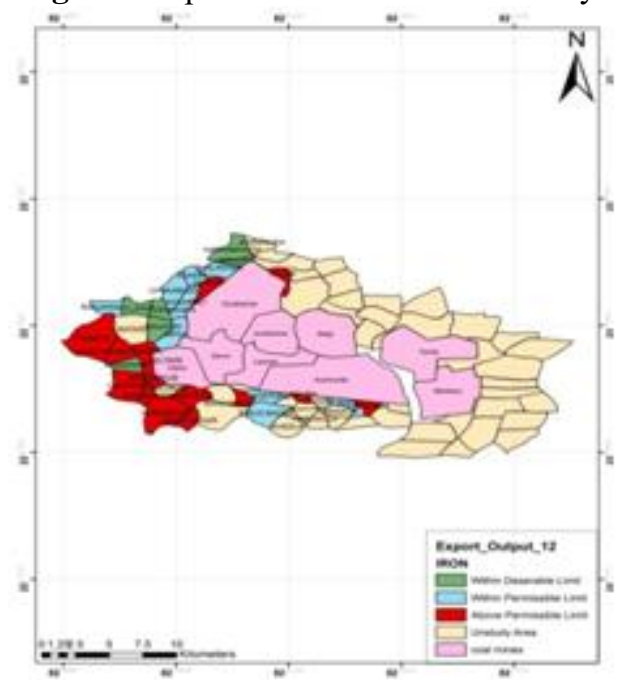

Figure 6: Spatial distribution of iron.

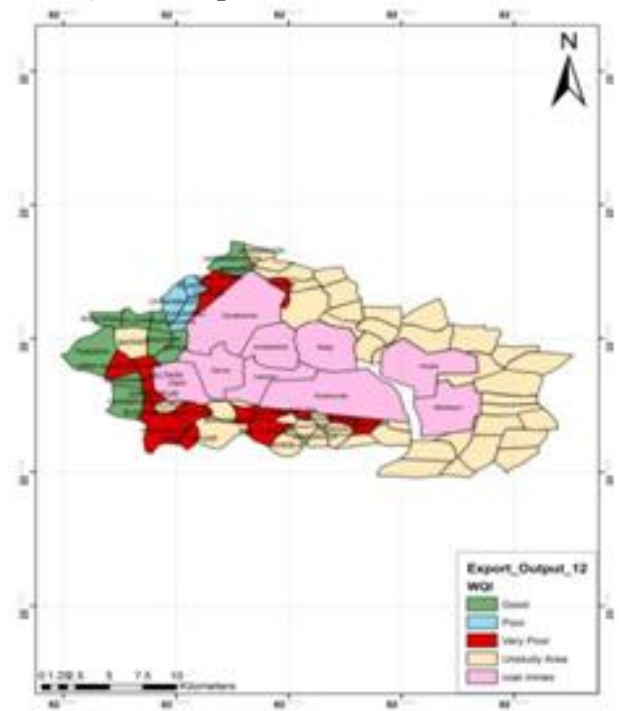

Figure 7: Spatial distribution of WQI.

\subsection{Parameter Sensitivity Analysis}

The attribute sensitivity analysis indicates that perturbations introduced into all the nine parameters have caused changes in the WQI output. The variations mainly for the parameters like $\mathrm{pH}$, iron and turbidity is shown in figures from 8 to 13 . The output index of both perturbed and unperturbed 


\section{International Journal of Science and Research (IJSR) \\ ISSN (Online): 2319-7064}

Index Copernicus Value (2013): 6.14 | Impact Factor (2014): 5.611

variations reflects that $\mathrm{pH}$, Turbidity and Iron are the most influencing parameters whereas chloride and calcium has minor impact. Out of 30 villages, 08 villages are highly affected by $\mathrm{pH}$ in the variations, bears acidic water and perturbation introduced to $\mathrm{pH}$ causes maximum change of $43.33 \%$, followed by 13 villages possessing Iron content more than permissible limit and the maximum change due to perturbation is $10 \%$. The concentrations of turbidity are not within the range for most of the villages. Most of the villages have high turbid waters. 18 villages have turbid water. These are the three main leading parameters that make water non potable for drinking. $\mathrm{NO}_{3}{ }^{-}, \mathrm{Ca}^{2+}, \mathrm{Cl}^{-}$, TDS, $\mathrm{TH}, \mathrm{Fl}$ has the minimum contribution in output index. From the output index it shows that out of 30 villages total 17 no of villages are highly affected by WQI (200-300) i,e very poor for drinking in both perturbed and unperturbed index. The maximum change of attribute values for perturbed index is $13.33 \%$, i,e according to sensitivity analysis 17 no of villages are very sensitive and needs more monitoring and necessary steps must be taken. WQI maps obtained after sensitivity analysis is shown in Figure no. 14 and 15.

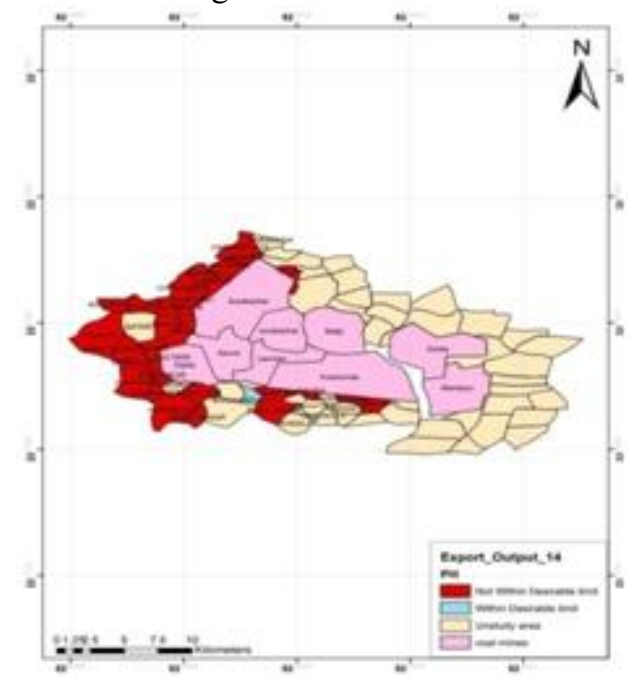

Figure 8: Spatial Distribution of $\mathrm{pH}$ after variation 1

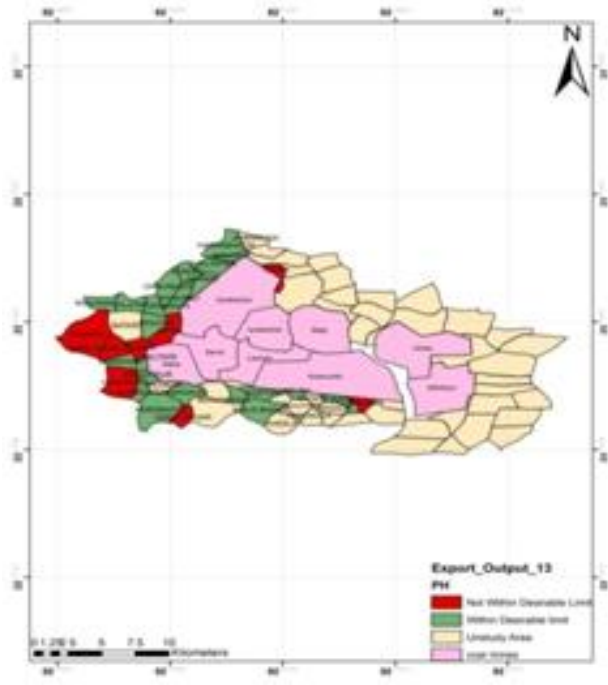

Figure 9: Spatial Distribution of $\mathrm{pH}$ after variation 2

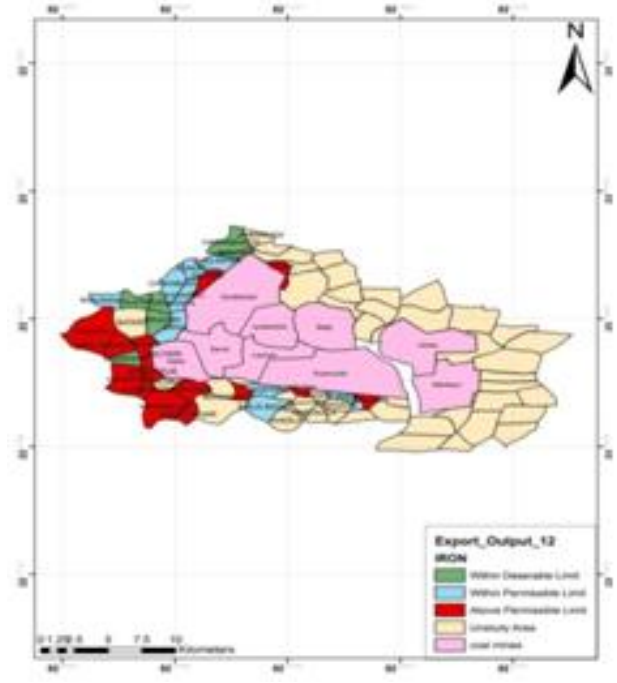

Figure 10: Spatial Distribution of iron after variation

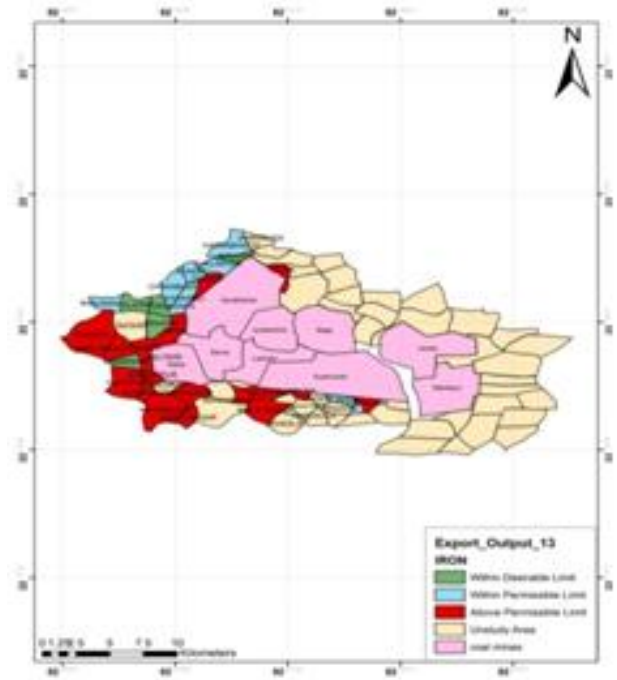

Figure 11: Spatial Distribution of iron variation 2

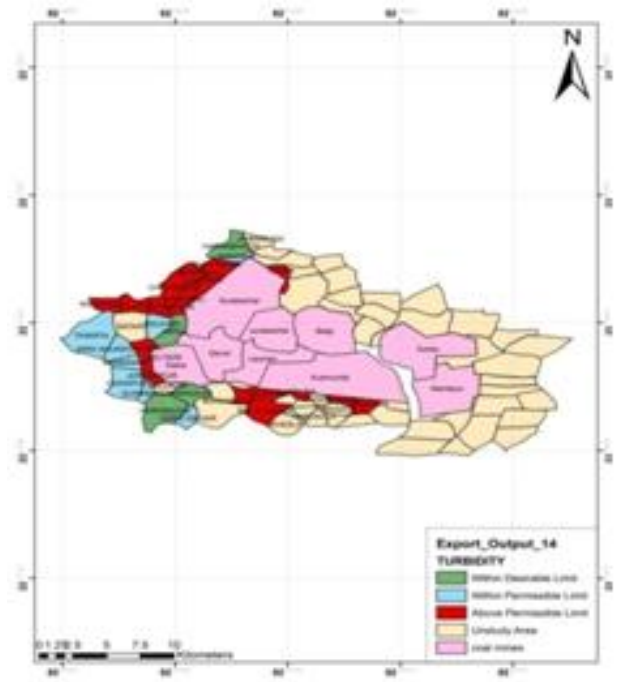

Figure 12: Spatial Distribution of Turbidity after variation 1 


\section{International Journal of Science and Research (IJSR) \\ ISSN (Online): 2319-7064}

Index Copernicus Value (2013): 6.14 | Impact Factor (2014): 5.611

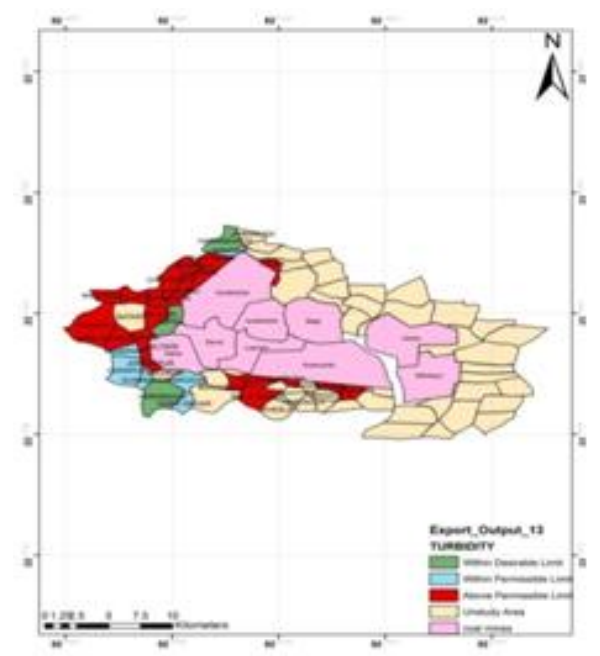

Figure 13: Spatial Distribution of Turbidity after variation 1

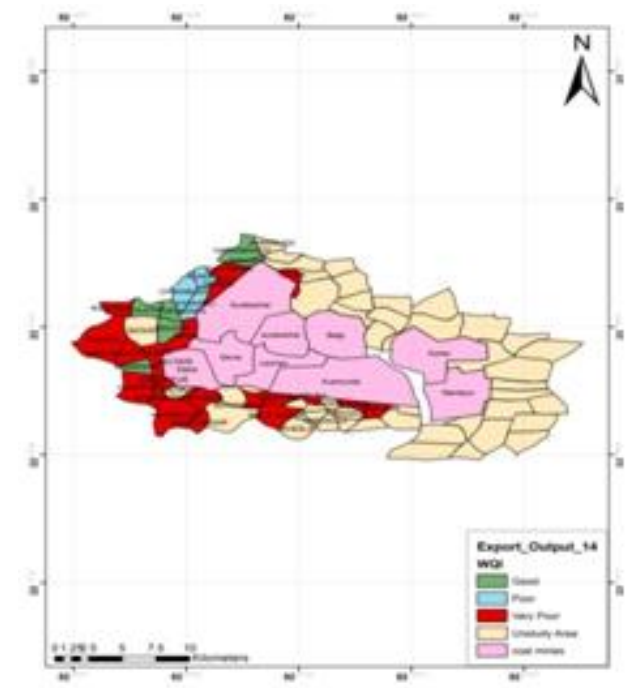

Figure 14: Spatial Distribution of WQI after variation 1

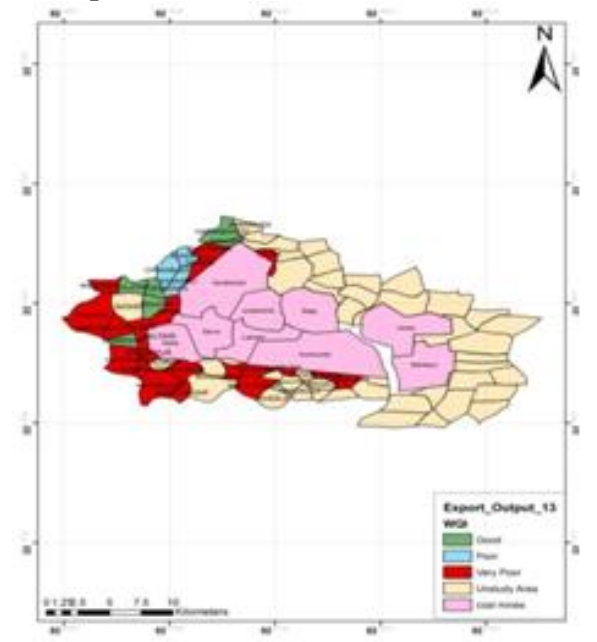

Figure 15: Spatial Distribution of WQI after variation 2

\section{Conclusions}

In the present work, an attempt was made to evaluate and to map the groundwater quality surrounding mining region in Korba district. The estimated WQI provides an easy way of understanding the overall portability of water quality. The integration of various thematic layers with the help of Arc GIS 9.3 is of immense help in determining suitability of ground water quality for drinking purpose.Most of the areas are highly affected by three parameters such as $\mathrm{pH}$, Iron and Turbidity. All the three parameters present in water are above permissible limit. It is observed that Fluoride concentration is high in only Dewgaon village, above desirable limit. All villages are found to be having chloride concentration within desirable limit.Out of thirty villages, Only ten locations had a satisfactory result of WQI below 100 , water present in seventeen other locations are found to have very poor water bearing WQI 200 to 300 and rest three villages come under poor grade. The model sensitivity analysis indicated that parameters which reflect relatively lower water quality and those of significant spatial variability imply larger impacts on the WQI.

\section{Acknowledgement}

The authors are thankful to CCOST, Raipur for providing us valuable data.

\section{References}

[1] Ahn H, Chon H (1999). Assessment of groundwater contamination using geographic information systems. Environ. Geochem. Health, 21: 273-289.

[2] Anbazhagan, S., \& Nair, A. M. (2004). Geographic information system and groundwater quality mapping in Panvel Basin, Maharashtra, India .Environmental Geology , 45(6), 753-761.

[3] BIS (Bureau of Indian Standards) 10500, Indian standard for drinking water specification, 1991, first revision, $\mathrm{p}$ 1-8.

[4] Bonham-Carter GF (1996) Geographic information systems for geoscientists: modeling with GIS methods in the geosciences, vol 13. Elsevier Science Ltd, Pergamon, pp $1-50$.

[5] Cude, C. 2001. Oregon water quality index: A tool for evaluating water quality Management effectiveness. Journal of the American Water Resources Association, 37, 125-137.

[6] Ducci D (1999). GIS techniques for mapping groundwater contamination risk. Natural Hazards, 20: 279-294.

[7] Hong, I. A., \& Chon, H. T. (1999). Assessment of groundwater contamination using geographic information systems. Environmental Geochemistry and Health, 21(3), 273-289.

[8] Hulya, B.2009, Utilization of the Water Quality Index method as a classification tool, Environmental monitoring and assessment.

[9] Lo CP., Yeung AKW., 2003. "Concepts and techniques of geographic information systems New Delhi": Prentice-Hall of India Pvt. Ltd, p. 492.

[10]Lodwick WA, Monson W, and Svoboda L (1990) Attribute error and sensitivity analysis of map operations in geographical information systems: Suitability analysis, Inter J Geogr Inform Systems 4(4):413-428.

[11] WHO (World Health Organization) Guidelines for drinking water quality., 1983, $2^{\text {nd }}$ Edition, vol 1, p-188.

[12] WHO, World Health Organization (2004) Guidelines for drinking-water quality, vol 1, 3rd edn, recommendations. WHO, Geneva, Switzerland, pp 145220. 